\title{
Design modification and performance testing of solar assistive electric vehicle
}

\author{
Sudan Neupane ${ }^{a, *}$, Pankaj Joshi ${ }^{b}$, Subas $\mathrm{Badu}^{b}$, Rohit Kumar Kalauni ${ }^{b}$ and Bijay \\ Prakash $\mathrm{Rajak}^{b}$ \\ ${ }^{a}$ Department of Industrial Engineering, Thapathali Campus, Institute of Engineering, Tribhuvan University, Kathmandu, Nepal \\ ${ }^{b}$ Department of Automobile and Mechanical Engineering, Thapathali Campus, Institute of Engineering, Tribhuvan University, Kathmandu, \\ Nepal
}

\section{ARTICLE INFO}

Article history:

Received 09 Jan 2021

Received in revised form

$09 \mathrm{Feb} 2021$

Accepted 16 Feb 2021

Keywords:

Ecofriendly

Solar Power

Solar Assisted

Electric Vehicles

Renewable Energy

\begin{abstract}
One of the front runners in the area of renewable energy today is solar power. It is a cheap and ecofriendly means of power generation. Solar power is converted into electrical energy using photovoltaic cells. This harnessed electrical energy can be used to charge battery of EV. The objective of this project is to convert IC trike into electric vehicle and then assisted by using solar energy so that the range of the vehicle can be increased. This project involved the performance testing of an electric vehicle along with comparison with solar assisted. The vehicle we used is a single seated IC trike with skeleton structure generally used for racing purposes. The aim was to implement our idea on an IC trike and afterwards with help of result obtained to extend our future work on building a real time solar assisted electric vehicle. During the testing it is found that the electric trike operate at maximum speed of $38.4 \mathrm{~km} / \mathrm{hr}$. with $17.29 \mathrm{~km}$ range and $21.28 \mathrm{~km}$ while solar assisted with speed of $34.5 \mathrm{~km} / \mathrm{hr}$. The solar assisted EV in turn resulted an increment of mileage by $23 \%$ and the additional money invested will be returned in 7.8 years. Conclusively, the solar assisted EV gained range while having a decrement in speed of the vehicle. The overall experiment favored the solar assisted EV.
\end{abstract}

\section{Introduction}

Solar Vehicles refers to the production of electricity through solar energy using photovoltaic cells (PVC) which is then stored in batteries. The trike runs by using the energy stored in battery. PVCs are the components in solar panel and are made up of semiconductor, usually of silicon that absorbs the light. Electricity so produced is used to drive the motor of the vehicle. Three wheeler is a vehicle with three wheels. The advantage of a three wheeler is that it has quite a small turning radius as compared to a four wheeler with same track (lateral distance between wheels) and wheelbase (longitudinal distance between axles). Three wheeler are more efficient than four wheeler of same weight. Lesser rolling resistance means greater mileage. It is quite beneficial over aerodynamic drag. Electric Vehicles were introduced in

\footnotetext{
*Corresponding author:

@ neupanesudan@ioe.edu.np (S. Neupane)
}

CJIEE Thapathali Campus, IOE, TU. All rights reserved

Kathmandu in 1975 when the Chinese Government set up the trolley bus system along the $13-\mathrm{km}$ route between Tripureswor and Surya-Binayak. After that, the EV movement took off in 1989, when a fuel crisis resulting from the India imposed trade embargo prompted a group of engineers to find an alternative arrangement for transportation.

The group called the Electric Vehicle Development Group converted an old car into an EV in 1992. In 1993, the Global Resources Institute, with assistance from USAID, began a program to develop EVs as a profitable industry. The project converted 7 polluting diesel operated threewheelers into EVs (Safa Tempos), and successfully operated them as public vehicles for six months. Currently, over 600 Safa Tempos are plying on the streets of the valley and there are five EV manufacturers. Following rapid growth in the late 1990s, the EV industry has been unable to grow further in the last few years mainly because of conflicting government 


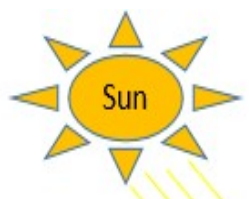

Solar Radiation

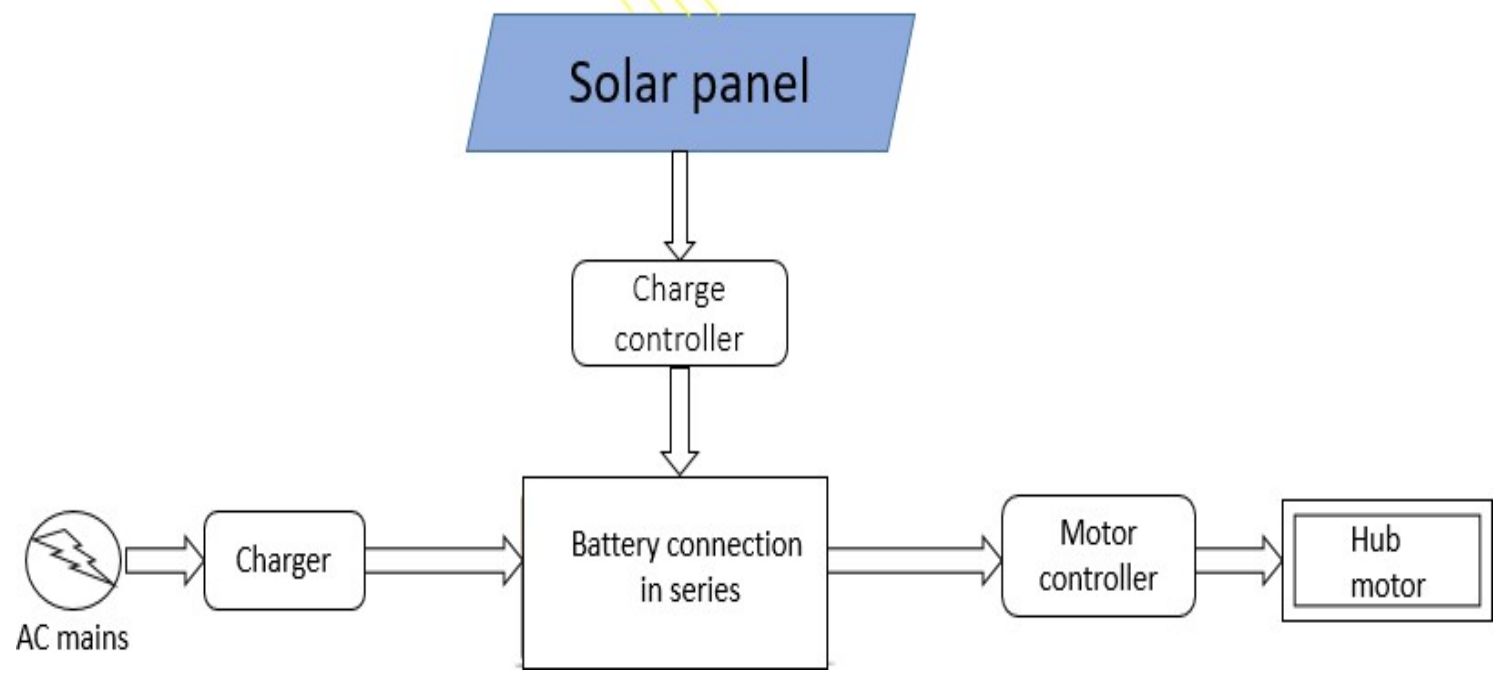

Figure 1: Basic block diagram representation of Solar Vehicle

policies and high operation costs. But nowadays the automobile company like Mahindra, Hyundai, Kia are introducing electric vehicle in Nepal because of increasing interest of customer toward renewable energy. Nepal receives $4.7 \mathrm{kWh} / \mathrm{m}^{2}$ solar energy per day [1] making it a favorable source of energy. Still the solar technology in field of vehicle is yet to be discovered as there is no such recognizable research in the field of solar EV in Nepal

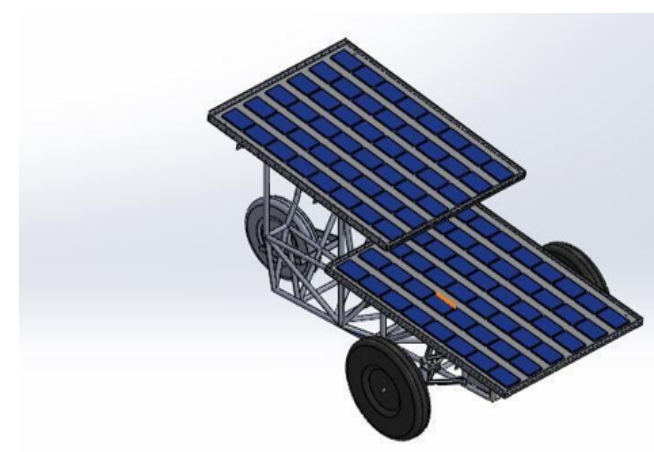

Figure 2: Design modification of three wheeler

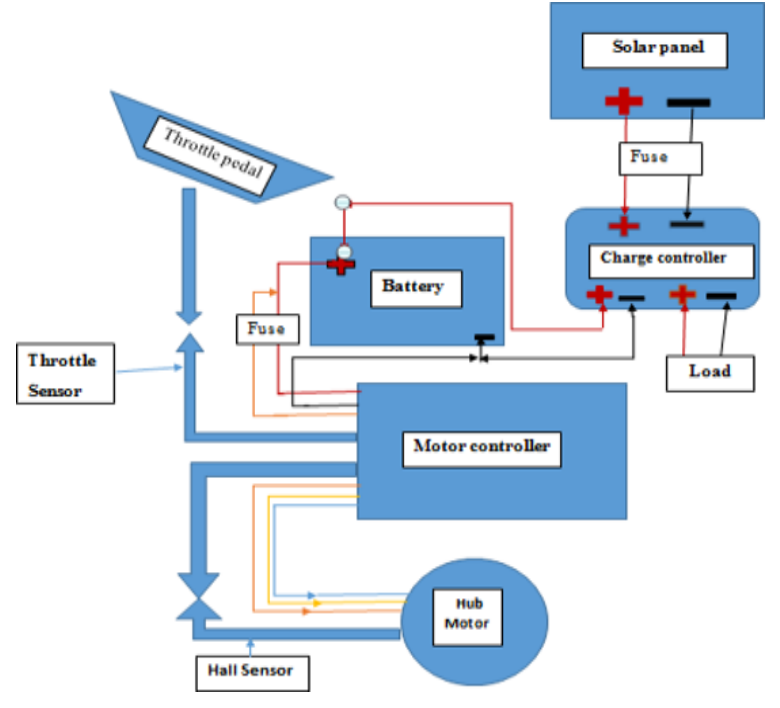

Figure 3: Working principle of solar assistive electric vehicle

\section{Literature Review}

Since the beginning of the industrial revolution, the rate of energy consumption has increased at an alarming rate due to skyrocketing consumption by industries and general population. This situation can be overcome with 
mass production of the photovoltaic (PV) cell which uses solar energy with low fluctuation converted into electrical energy. Solar energy is one of the important sources of renewable energy which can be a feasible alternative to fossil fuels. Many works has been done in order to incorporate solar energy to every day transportation. The electrical energy is obtained by converting the sun's energy by the photovoltaic (PV) cell. By using this method, solar vehicles can be run to reduce the pressure on the energy sector ultimately reducing the effect of carbon emissions. "A Solar Vehicle Based On Sustainable Design Concept" describe the integration of the off-the-shelf mechanical and electrical components for the solar vehicle. The solar cars used two front wheels with effective steering and suspension systems, a rear wheel with built-in direct current (DC) motor and aerodynamic body shape that had resulted in high speed solar cars, capable of reaching a top speed of $120 \mathrm{~km} / \mathrm{h}$ and able to complete the race of $3000 \mathrm{~km}$ distance form Darwin to Adelaide in 4 days [2].The paper entitled "Design and Development of Solar Assisted Bicycle" was written by an Indian student of Tirupathi. The product, a solar assisted bicycle, was driven by a DC motor fitted in the front or rear axle housing \& operated by solar energy. The solar panels mounted on the carriage charged the battery which in turn drove the hub motor. When the bicycle was idle, the solar panel charged the battery. The solar assisted bicycle had a power rating of $250 \mathrm{~W}$ and travelling speed of around $25-30 \mathrm{~km} / \mathrm{h}$ [3].

\section{Methodology}

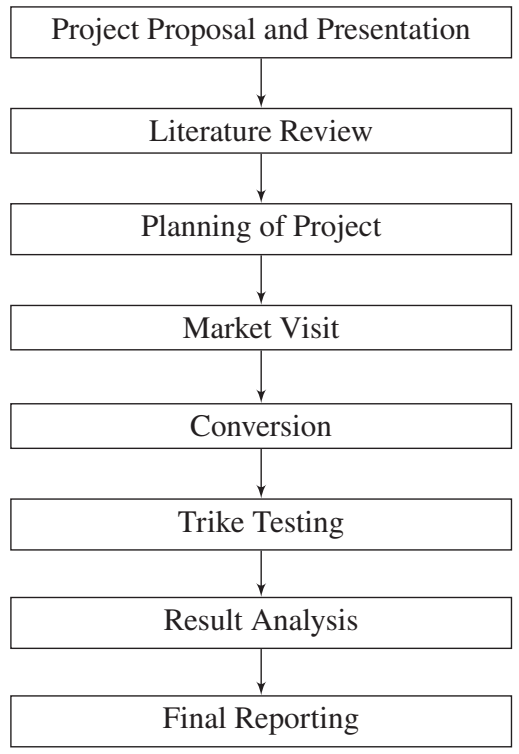

Figure 4: Flowchart showing Methodology of Study

\section{Result Analysis}

This is the section where actual performance testing is done. It includes basic analysis about performance of electric trike and solar assistive electric trike. The obtained data and the graph show that with the installation of solar assistive system on the electric trike, its performance gets changed. With addition of solar around 31 $\mathrm{kg}$ of the weight is added to the trike so the velocity of solar assistive system decreases but the current drawn, power used and torque increases at same throttle angle in reverse and forward direction of the vehicle.

The obtained data and the graph shows that the current, RPM, power drawn increase linearly with the throttle angle. At higher angle of throttle the all values get saturated. At no load condition only $161 \mathrm{~W}$ power is used from battery in forward and $44.61 \mathrm{~W}$ in reverse condition at maximum throttle. The current consumption and the RPM of the motor is less in reverse condition then in forward direction.

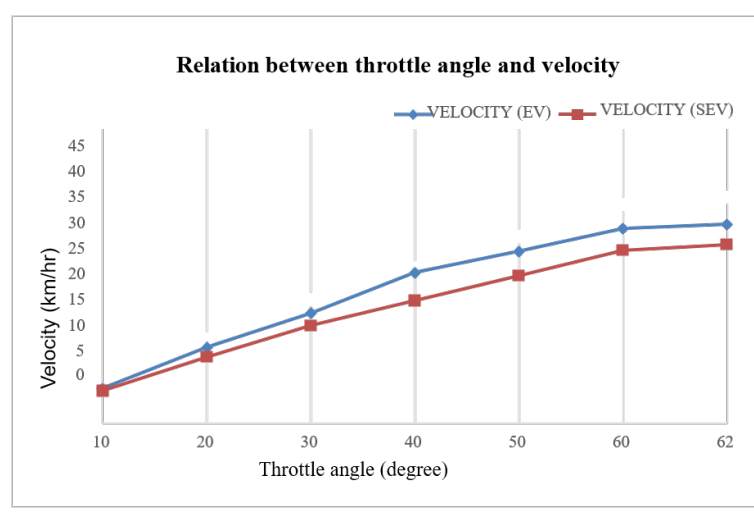

Figure 5: Relation between throttle angle and velocity

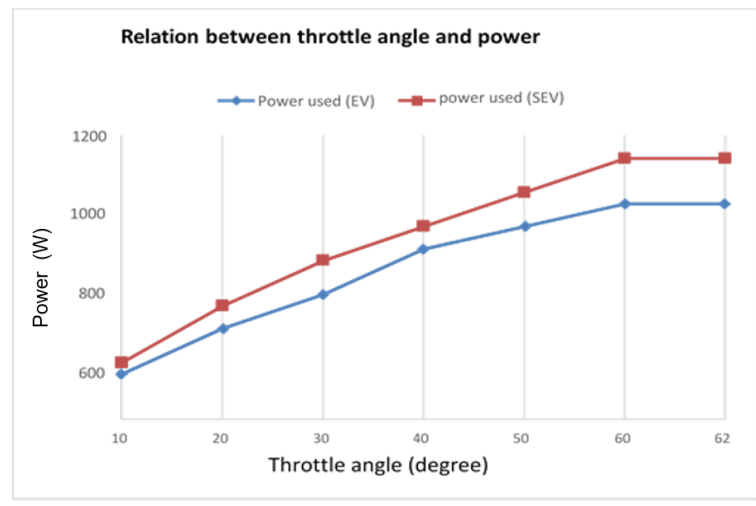

Figure 6: Relation between throttle angle and power 


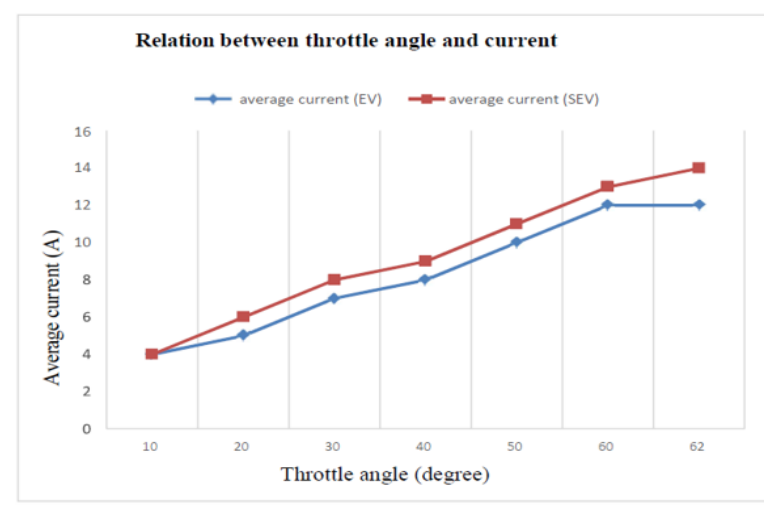

Figure 7: Relation between throttle angle and current

\section{Conclusions and Recommendation}

Performance testing of electric trike showed the maximum speed of trike to be $38.4 \mathrm{~km} / \mathrm{hr}$. and ranges up to $17.29 \mathrm{~km}$. Similarly, maximum speed while addition of solar panel was found to be $34.5 \mathrm{~km} / \mathrm{hr}$. with range of $21.28 \mathrm{~km}$. The overall comparison between electric trike and solar assisted trike concluded in increment of range by $23 \%$. The additional money invested on installing the solar to electric trike will return in 7.8 years. As solar panel lasts up to 20 yrs., the further benefit will be of free of cost. As mentioned on objectives of the project, the result seems to fulfill its quest. So the modification done in this trike bought the positive result.

Although the main objective of this project is to convert a pre-existing 3 wheeled trike, the main focus is to assist any electric vehicles. The idea is to apply this result on commonly used electric vehicles. So, some of the recommendations for better improvement of results are stated as:

i Use of lithium ion battery for reducing weight.

ii Use of flexible solar panel to use it as the super structure.

iii Use of efficient solar charge controller to track maximum power from sun.

iv Use of high power motor for high performance.

$\mathrm{v}$ The BMS system can be used for increasing battery performance.

vi Mono crystalline solar panel can be used for high performance.

\section{Acknowledgement}

This report would not be possible to complete without the help of a number of people during the research study. We would like to take this great opportunity to acknowledge them. we would like to acknowledge the contributions of our Campus (IOE Thapathali Campus) and the university. Our sincere thanks go to the Campus Chief of IOE Thapathali Campus Er. Janardan Bhatta for the institutional support. He also supported us by giving me the permission to visit the experimental site for conducting research work. Last but not least, we would like to thank the experts from university grants commission for selecting this research work and giving us the grants to carry the research work

\section{References}

[1] Adhikari K R, Gurung S, Bhattarai B K. Solar Energy Potential in Nepal and Global Context[J/OL]. Journal of the Institute of Engineering, 2014, 9(1): 95-106. DOI: https://doi.org/10.3126/ jie.v9i1.10675.

[2] Taha Z, Md. Sah J, Passarella R, et al. A solar vehicle based on sustainable design concept[C]// Proceedings of the IASTED International Conference on Solar Energy, SOE 2009. 2009: 38-43.

[3] Sankar M R. Design and Development of Solar Assisted Bicycle $[J]$. International Journal of Scientific and Research Publications, 2013, 3. 